\title{
O FENÔMENO JURÍDICO COMO OBJETO DE UMA ONTOLOGIA FUNDAMENTAL ${ }^{*}$
}

\author{
Jeannette Antonios Maman \\ Professora Doutora do Departamento de Filosofia e Teoria Geral \\ do Direito da Universidade de São Paulo; professora do Centro \\ de História das Ciências da Universidade de São Paulo
}

Resumo:

É na carência, situação-limite, que se revela (se desoculta) o autêntico Direito, aquele que supre a falta de bens materiais, corpóreos e incorpóreos, e promove a igualdade pelo atendimento das necessidades vitais do ser-aí outro, constitutivamente igual ao mesmo. É no atender às necessidades existenciais do outro, que sofre privações nas coisas e na sua pessoa, que se revela o jurídico autêntico.

Abstract:

The privation of people's needs reveals the authenticity of the law. The law that provides material or immaterial things to supply needfulness of the human being, adjusting differences.

Therefore, the law can be defined not only as a social and cultural product but also as a matter of survival.

Unitermos: Direito; filosofia; hermenêutica; ontologia; Heidegger.

Sumário:

1. A pesquisa ontológica e o seu sentido geral; 2. Pressupostos ontológicos para uma investigação fenomenológica do Direito; 2.1. Ordem jurídica; 2.2. Povos; 2.3. Expressão; 2.4. Situação existencial.

* Este trabalho, em suas linhas gerais, foi apresentado no $13^{\circ}$ Colóquio da International Association for the Semiotics of Law, FDUSP, São Paulo. 
1. A pesquisa ontológica e o seu sentido geral

A ontologia fundamental tem como tarefa esclarecer a questão do ser, a questão mais geral e mais concreta - a mais concreta porque decide do ser do ente que a põe. A generalidade da pesquisa ontológica dá-lhe um sentido mais amplo do que as investigações ônticas das ciências positivas, pois propõe indagar da condição do ser e não do significado do ente. É a volta às origens gregas, onde o pensamento ocidental tem início com a questão do ser, aqui retomada, não como ontologia clássica, mas como ontologia fundamental pensar após Heidegger.

Ver o Direito como fenômeno da ontologia fundamental é vislumbrar a hipótese de o fenômeno jurídico existir na esfera autêntica.

Ainda que o Direito não-constitua tema expresso em Heidegger, o seu pensamento, em sua lógica virtual, permitiria ver o Direito na sua forma, segundo Maihofer, apenas inautêntica, na analítica da forma decaída do existir autêntico, no modo do ser-aí cotidiano, da perda no se. Ora, bem ao contrário, assegurada a liberdade do ser-aí na modalidade do jurídico inautêntico (que ainda assim abarca a solicitude o cuidado), é possível pensar a atualização da possibilidade mais autêntica do ser-si-mesmo, em um Direito autêntico. Nada impede a realização do "torna-te a ti mesmo" (torna-te aquilo que és) no Direito. ${ }^{1}$ Não há separação entre os modos de ser autêntico e inautêntico na constituição do ser-aí, e isso fica expresso em Heidegger: "A ipseidade autêntica não repousa sobre nenhuma situação de exceção, que sobreviria a um sujeito libertado do jugo do 'se'; não é senão uma modificação existencial do 'se' definido como um existencial essencial" 2

A questão fundamental põe-se na pesquisa do Direito: qual o ser autêntico do jurídico?

Uma proposta alternativa ao ecletismo e ao reducionismo jurídico é a de tomar o fenômeno jurídico como objeto de uma ontologia fundamental, a ordem

1. A expressão "torna-se a ti mesmo" está no Fausto de Goethe (1749-1832), da qual parece apropriar-se Freud (1856-1939) "sê o que tu és" - que em Totem e tabu, (p. 188) já citara Fausto: "Aquilo que herdaste de teus pais, conquista-o, para fazê-lo teu" (parte I, cena I). Seria retomada a expressão "como tornar-se o que se é", em Nietzche (1844-1900) no Ecce Homo, que na tradução portuguesa de Artur Mourão (Lisboa, Edições 70, 1989) aparece deste modo: como se vem a ser o que se é (subtítulo de Ecce Homo) e 49: como se chega a ser o que se é em Ser e tempo (parte I, Vozes, Petrópolis, 1988), p. 201.

2. Heidegger, Martin. Apud Aloysio Ferraz Pereira, Estado e Direito na Perspectiva da Libertação, São Paulo, Editora Revista dos Tribunais, 1980, p. 192. 
jurídica como expressão da situação existencial dos povos. Tal ordem jurídica resulta de ser o Direito não um conjunto de normas mas, antes, a pesquisa do justo, o acesso à Justiça pela observação e pela intuição, que é percepção racional e até intuição sensível, aquela da sensibilidade artística. Em última análise, o jurídico é alcançado pelo homem existente (o ser-aí, o Dasein) em sua constituição fundamental, isto é, dentro da sua estrutura existenciária a que se dá o nome de compreensão, a qual se desdobra nos fenômenos sucessivos da explicitação (Auslegen) e interpretação. A visão ôntica (empírica) do fenômeno jurídico é abrangida pela visão ontológica, fenomenológica-existencial.

Na atualidade é em Heidegger que se coloca a questão do ser. É a partir do seu pensamento que podemos chegar à afirmação de que o Direito autêntico é a expressão da situação existencial do ser-aí.

É na carência, situação-limite, que se revela (se desoculta) o autêntico Direito, aquele que supre a falta de bens materiais, corpóreos e incorpóreos, e promove a igualdade pelo atendimento das necessidades vitais do ser-aí outro, constitutivamente igual ao mesmo. É no atender às necessidades existenciais do outro, que sofre privações nas coisas e na sua pessoa, que se revela o jurídico autêntico.

Nesse desvelar tem importância a consciência moral do ser-aí, que aceita sua própria nulidade e sua culpabilidade fundamental. ${ }^{3}$ Não se exclui do Direito a "ressonância da subjetividade" 4 capaz de compreender, diante do rígido Direito Positivo, quais os meios hábeis para assegurar ao outro a realização de suas possibilidades. Assim, a atividade jurisprudencial não-exclui certa ética, enquanto filosofia prática, que implica habilidade, arte no agir. ${ }^{5}$

3. Pereira, Aloysio Ferraz. Estado e Direito na Perspectiva da Libertação, São Paulo, Editora Revista dos Tribunais, 1980, pp. 199-200.

"O ser-culpado não resulta apenas de uma inculpação, mas ao inverso: esta só é possível sobre o fundamento (em razão de) um ser-culpado original. Assim, a culpabilidade do ser-aí, que é fundamento dos atos culposos, pecados e crimes que ele comete, tem por sua vez, como fundamento, uma negatividade, uma carência, que reside nele mesmo. E esta negatividade, este nada, inerente, original e constitutivo do ser-aí, vale dizer, do seu cuidado, manifesta-se quando vos translucidamos a nós mesmos (em nosso próprio ser)".

4. Cf. op. cit., p. 190.

5. Não se exclui, na ontologia fundamental, o agir sobre si mesmo, uma espécie de "fazer-se" a si mesmo, uma filosofia de vida prática, que já entre os gregos era moral social. Daí a recorrência neste trabalho a Aristóteles o retorno ao passado, a retomada é um modo subversivo de ser, pois se vai fundo na questão existencial. Retoma-se e restaura-se Aristóteles, para avançar com Heidegger, na questão do ser. 
Não é difícil o encontro do modo autêntico do ser jurídico: a Justiça. A noção de Justiça no pensamento grego, em Platão e Aristóteles, é definida brevemente na "regra de ouro": o seu a cada um, que passa para o Direito Romano com Ulpiano "Iustitia est constans et perpetua voluntas ius suum cuique tribuendi" 6 Daí deriva ser injustiça não dar a cada um o seu, ou seja, na base da injustiça encontra-se a privação no patrimônio, nas coisas corpóreas ou incorpóreas, nos bens ou na pessoa de outrem; portanto, tudo muito concreto, não há abstração na referência do "seu" O suum cuique, em Aristóteles e no Direito Romano, não se funda sobre o conceito de Direito Subjetivo, que é estritamente moderno, mas sobre a distribuição justa dos bens, riquezas e ônus da sociedade é o Direito Natural como método "experimental" método que conduz ao encontro das soluções justas, adequadas e úteis, baseado nas virtudes da Justiça e da prudência, esta disposição sui generis entre a ciência e a arte, que tem muito desta e bastante da filosofia, sem deixar de participar da ciência. ${ }^{7}$

A Justiça é o modo exigente da juridicidade, que tem raiz ontológica, no cuidado $^{8}$ e na culpabilidade assumida do ser-aí. Como virtude, a Justiça é "disposição permanente do querer o bem" bem que não-coincide com o homem, mas tem que ser realizado em si próprio, por esforço e energia em buscá-lo, pelo trabalho e pela arte. O bem pressupõe uma relação ao outro. O movimento de buscar o justo é uma espécie de tekhné, um fazer-se (esforço) e um fazer dirigido ao outro (arte). O seu a cada um perderia o sentido se o critério da atribuição fosse o mérito, como em Aristóteles, pois a analítica existencial do ser-aí, na seqüência de Heidegger, leva-nos a verificar que o homem não tem mérito algum. Os homens são iguais em sua nulidade. Para a realização da co-existência é preciso também deixar que cada um seja aquilo que é, supridas as necessidades vitais de alimento, abrigo, saúde, educação, que permitem igualdade social, política e jurídica. "De cada qual conforme sua capacidade, a cada qual segundo suas necessidades" aquém de Aristóteles e um pouco antes de Heidegger.

A realização da Justiça funda-se sobre o modo constitutivo do ser-aí, sobre o existencial, que é ser-com-outrem e permite a juridicidade da existência

\section{Digesto, 1, 1, 10.}

7. Cf. Villey, Michel. Leçons d'histoire de la Philosophie du Droit, Paris, Dalloz, 1962.

8. Cf. Heidegger, Martin. El Ser, y el Tiempo. Tradução de José Gaos, México, Fondo de Cultura Económica, 1951, pp. 133 a 142. 
autêntica o modo autêntico do ser jurídico. É, pois, a ontologia que fundamenta a igualdade política e jurídica na existência autêntica, pelo reconhecimento da recíproca alteridade dos coexistentes.

Definição de Justiça ou do jurídico, à luz dessa filosofia: modo de ser do ser-aí, no-mundo-com-os-outros.

A experiência constitui a base principal e a primeira condição do conhecimento; a constituição prática do homem existente permanece o essencial.

"A primeira conseqüência de ordem política a ser derivada da filosofia de Heidegger é a igualdade de todos os homens porque ontologicamente fundada na constituição originária do ser-aí. O método fenomenológico praticado pelo filósofo permite alcançar o universal concreto através do singular, isto é, descortina a inteligibilidade e o ser de todo o homem pela via da análise existencial ou ontologia fundamental" 9 Este singular, o ser-aí, não é indivíduo, é o ser-com, o ser-aí que se constitui no-mundo-com-o-outro. É o homem existente na sua condição solidária, na vontade permanente de estar junto, ou melhor ainda, de ser o mesmo. ${ }^{10}$

\section{Pressupostos ontológicos para uma investigação fenomenológica do Direito}

\subsection{Ordem jurídica}

Consideramos a ordem jurídica e não-ordenamento, que poderia referir-se tão-somente ao sistema normativo, nem leis, que poderiam ser relacionadas às instâncias arbitrárias de decisão e poder, nem tão pouco Direito, que pode ser visto apenas como conjunto de normas.

É um tornar a si mesma, esta ordem jurídica, que não-abandona a existência cotidiana do ente humano existente. Para bem entendê-la é necessário manter o interesse pela leitura dos jornais ("a moral é o jornal" é o se, o impessoal, é toda a gente, são todos os outros); é neles que se retrata a face do homem comum.

\section{Cf. Pereira, Aloysio Ferraz. Op. cit.}

10. Heidegger, Martin. Op. cit., p. 141: "El 'ser relativamente a otros', sin duda es bajo el putno de vista ontológico, distinto del 'se relativamente a cosas ante los ojos'. El 'otro' ente tiene él mismo la forma de ser del 'ser ahí. En el 'ser com' y 'relativamente a otros' hay, pues uma 'relación de ser' de 'ser ahi' a 'ser ahi'. Pero esta relación, cabría decir, es la constitutiva del 'ser ahi peculiar en cada caso, que tiene uma comprensión de su peculiar ser y se conduce así relativamente al 'ser ahi' El 'ser relativamente a otros' se torna entonces 'proyección' del peculiar 'ser relativamente a sí mismo' en otro. El otro es una doublette del símismo" 
Se buscamos a face de Sein, se buscamos o ser no homem, não podemos deixar o se (o man alemão, o on francês), como expressão do homem comum, que queremos preservar e garantir como essencial ao homem existente. $\mathrm{O}$ que importa, também, é a existência cotidiana do ente humano, do Dasein.

A reflexão sobre o compromisso do extraordinário com o cotidiano (a necessidade de aproximar o inautêntico do autêntico) nasce das leituras diárias de jornal, da informação recebida pelos veículos de divulgação que registram e promovem a banalização da violência, da miséria, da fome e das guerras (que pela TV terminam por transformar-se em "videogame") "é a banalização da tragédia" 11

Como se não-bastasse a crueza dos fatos, o noticiário manipula a opinião pública. Assim é com a pena de morte, retrocesso na história da humanidade. Se todos os argumentos contra fossem refutados, bastaria um só, de ordem lógica: não se justifica, em nome da vida, condenar à morte.

Entre o autêntico e o inautêntico não há o nada. Pode-se reduzir ou entender o Direito Positivo somente como a busca ou realização do inautêntico, do utilitário, do manipulável, do utensílio. Não menos inautêntico é o objeto da ciência (o que se põe como objeto da ciência); assim, o Sol, descrito pela ciência, não é a luz que uso ou o calor que procuro, como não é também a divindade incaica é uma estrela de quarta grandeza. Eis a diferença entre o manipulável, o "à mão" (das Zuhandenheit) e o subsistente, o "diante da mão" (das Vorhandenheit), o objeto da ciência.

A saída para assegurar um terreno comum entre o manipulável (disponível) e o subsistente (o que se põe diante), o "lugar" onde encontramos o Direito justo - é o âmbito que constitui o objeto da arte.

Podemos conceituar arte, neste passo, como a atitude integral do homem existente ao deixar constituir-se um objeto, numa estrutura qualquer de ação, contemplação e conhecimento. O justo, a solução justa, é a obra de arte do jurista, como já o era no homem justo.

A arte, enquanto processo ou conjunto de modos de proceder, é o instrumento que nos dá acesso ao modo-de-ser-Justiça, o que coincide com a definição romana: ars boni et aequi. A arte libera a verdadeira essência dos entes, desvela o homem (individual ou coletivo) em seu ser, independentemente de sua 
utilidade ou do seu estatuto científico. É ela que "humaniza" digamos "existencializa" o homem em suas relações não é um instrumento passivo.

Este modo de compreender é o reconhecimento da vocação, servindo a esta, servir-se-á ao ser - um aspecto do ser manifesta-se originalmente quando a relação da atividade é criativa por isso o êxito acompanha aquele que conhece bem seu ofício.

A possibilidade de assim pensar o Direito contraria autores como Jaspers, para quem o Direito é todo ele inautêntico - é a parte social, é obra do se deixando a Justiça para a moral.

Uma ordem jurídica verdadeira procura aproximar o extraordinário (o autêntico) do cotidiano (o inautêntico). Esta ordem jurídica é o compromisso do extraordinário com o cotidiano: é o retorno à Justiça (de certa forma, ordem no sentido social global, estrutural, de Aristóteles, e não-convencional, como em Ockham, Hobbes, talvez mesmo, sob certo aspecto, em Rousseau - ordem espontânea e planetária, enquanto modo de preservar a vida no planeta).

A ordem jurídica justa possibilita a existência humana no mundo, existência material e espiritual. Contribui para que a vida-no-mundo possa afirmar-se e tornar-se como dever-ser, aquilo que é. O dever-ser visa restaurar ou manter os entes em seu ser. Falar em Direito é falar em vida, que é liberdade, nunca opressão. A ordem está em tudo, é abrangente, inelutável. Mas é também a liberdade que nos possui, uma vez que só no projeto existencial social encontra-se a abertura para a liberdade do ser. Numa ordem que é natural-existencial são realizáveis os projetos individuais.

Nesse sentido, é que podemos dizer que o Direito está mergulhado nas condições existenciais, na produção da vida material e espiritual, na situação em que o homem pode atuar sobre e com a natureza para subsistir. O Direito não é somente fenômeno normativo, isolado, abstrato, arrancado da vida, mas é ela mesma enquanto convivência humana, co-existência, compreensão compartida.

Tomaremos como ponto de partida de nossas reflexões a seguinte definição do fenômeno jurídico:

"É um modo de ser do ser-aí, enquanto este é, originária $e$ constitutivamente, ser-no-mundo e ser-com-outrem (Mitsein), bem como ser em comum e co-existência" 12

12. Cf. Pereira, Aloysio Ferraz. Op. cit., p. 168. 
Coloca-se assim a questão da "estrutura formal" da indagação filosófica: a quem se dirige (quem é perguntado) e sobre o que se pergunta.

No caso do ser social, pergunta-se sobre a sociedade, sobre a essência e $o$ ser do direito e a pergunta é feita à sociedade, enquanto modo de ser do ser-aí. Isto equivale a dizer que a pergunta tem que ser feita ao ser-aí, que é ser-no-mundocom-o-outro, originaria e constitutivamente, ${ }^{13}$ se não se cai na velha metafísica de Aristóteles e Habermas. Este, ao eliminar o subjetivismo (que atribui erroneamente a Heidegger), liquida também a filosofia, principalmente a alemã (ao jogar fora a água do banho, lá se vai junto a criança). Há em Heidegger uma forma aparentemente subjetiva, mas claramente social, quando na estrutura originária do ser-aí revela-se a sua condição de ser-com. Melhor isto se esclarece. ${ }^{14}$

"Aparentemente, nada está mais perto de um homem do que ele mesmo. Todavia, para que ele possa real e verdadeiramente compreender-se, é obrigado a compreender primeiro o mundo. Portanto, cada um de nós só chega à compreensão de si mesmo passando pela mediação do mundo e não-somente do mundo, mas também dos outros. Essa a aparência; a verdade porém é que o mundo e o outro são-nos dados simultaneamente e originariamente no próprio ser de cada qual. Ser para o homem, isto é, ser aí, significa ser com o mundo e ser com o outro".

Para a pesquisa do justo deve-se partir não do indivíduo isolado, mas sim da sociedade. O pensamento jurídico da individualidade não-corresponde ao serautêntico do Direito, que se perdeu com o sistema capitalista de produção. O indivíduo só será livre para suas possibilidades quando a sociedade também for: Qual é o autêntico fim da sociedade? Realizar a existência autêntica do ser-com: igualdade para a liberdade, ou ainda: liberdade igualitária.

Por outro lado, não se pode criar oposição entre grupos particulares e a sociedade total. A época é planetária, isto significa que não nos podemos voltar para a particular, mas quando vemos as manifestações dos nacionalismos europeus e a formação da Comunidade Européia não podemos deixar de refletir como o universal reduz excessivamente o homem ao social e que se deve preservar o individual, sob pena de desagregação social.

Quando Ockham diz que não há universais, só há indivíduos - o real existente é o singular e a sociedade um nome coletivo de indivíduos, o que ele quer

13. Heidegger, Martin. Op. cit.

14. Cf. Pereira, Aloysio Ferraz. Op. cit. 
é preservar o súdito, o cidadão, o sujeito, contra o Império e a Igreja. Quando Hobbes defende um individualismo, que é traído pelo absolutismo, ele considera absoluta sua análise. Se unirmos a lógica com os acontecimentos do tempo, poderíamos quem sabe "promover" esses dois ingleses a existencialistas, interpretando-os acima do que eles pensavam de si mesmos - e salvá-los... A perspectiva existencialista relativiza os fatos e faz que aqueles filósofos sejam vistos como homens de seu tempo. Assim, como epocais, têm de ser compreendidos.

Já em Durkheim se afirma a existência da sociedade com características diferentes dos indivíduos. É, de certo modo, o mesmo que dizer que a água não é simplesmente $\mathrm{H}_{2} \mathrm{O}$, oxigênio e hidrogênio; é uma combinação nova, algo diferente de seus componentes.

Por isso, quando buscamos o ser do Direito, vamos encontrá-lo na estrutura ser-no-mundo-com-o-outro. O ser do Direito não é o total nem o individual - é a estrutura originária do ser-aí como afirmação de co-existência.

A ontologia tradicional leva água para o moinho dos universais ou dos individuais. Ao contrário, na ontologia fundamental de Heidegger, o homem não é só ele ou o exterior - é as duas coisas, como o côncavo e o convexo do mesmo sólido geométrico. Não há exclusão de um modo de ser singular, interior, para privilegiar o modo de ser social.

\subsection{Povos (e não-Estado)}

Quando pensamos em um Direito para a América Latina, com hermenêutica apropriada, não introduzimos em sua representação nenhuma abstração ou símbolo, nem bandeiras, nações ou Estados. O nosso interesse está na afirmação e defesa do povo latino-americano e não da América Latina, isolada da convivência dos demais povos. Esse povo é objeto de um processo histórico de dominação e meio de enriquecimento dos povos do primeiro mundo.

A preocupação central é a distribuição e a participação na riqueza que permitam aos países periféricos ou marginais (em relação aos Estados centrais ou imperiais) mais gravemente aos países excluídos ${ }^{15}$ serem donos de seu próprio

15. Folha de S. Paulo (caderno Mundo) de 28.10.91 sob título: Nova Ordem Mundial cria império do norte contra "bárbaros" do sul. Subtítulo: apesar dos conflitos entre os novos blocos ricos, todos se unem contra a invasão da miséria.

A manchete do jornal se refere à obra de um historiador francês, Christophe Rufin, $O$ Império e os novos bárbaros, na qual expõe sua tese: o Império precisa de seu "duplo", de inimigos, para subsistir. 
destino, uma vez providas as condições de existência material e possibilitado o projeto social que permita a liberdade de ser em sua historicidade, e a superação, na situação internacional, do subdesenvolvimento. É a promoção de uma vida melhor, que se deve conter na ordem jurídica dos povos latino-americanos, como expressão de sua situação existencial.

Escolhemos, como direção à marcha de nossas reflexões, a ontologia de Heidegger que, ao pensar o ente em seu ser, permite que pensemos o Direito em devir no tempo e na história, enquanto busca e realização da Justiça. E isto, para as necessidades latino-americanas, significa identificá-la com a justa distribuição de bens e ônus sociais. E, em termos planetários, a Justiça alcança uma significação de co-existência para preservação da vida e do próprio planeta.

Se a polis aristotélica mantinha a coesão social pela equiitativa distribuição de bens e encargos, seu primeiro cuidado era a preservação de sua existência como bem comum. À sociedade política cumpria assegurar, com as virtudes dos cidadãos, a produção das condições existenciais na ontologia do Estagirita, ser e bem (que inclui a Justiça) são conversíveis, o que nos faz pensar em Aristóteles como um existencialista "avant la lettre"

\subsection{Expressão (manifestação)}

A ordem jurídica como expressão não é algo tirado do "mundo dos valores", algo ideal; não é naturalmente diferente da própria existência social.

Sobre as constantes axiológicas há aqui uma proposta de inversão a se fazer. Há variáveis axiológicas, mas há que se substituir o sestro de se falar em axiologia, que podemos esvaziar perguntando: Quem é o homem para fixar seus valores supremos? Qual o homem suficientemente bom para reformar seu semelhante, se não pode a si mesmo reformar? Proclamar o homem mesmo, e só, o seu valor supremo é a sua "suprema blasfêmia" Blasfêmia contra Deus, se quiserdes, contra o ser sempre em devir, contra o destino oculto e certo à nossa espera.

Assim, a ordem jurídica enquanto expressão é a manifestação de existência social do ser-aí; é o como do "tornar-se o que se é" nietzscheano, ou curiosamente concludente em tradução de Portugal "como se vem a ser o que se é"

Os que se encontram na "área devastada", com a qual o norte não tem qualquer interesse na profundeza do continente pouco importa quais sejam suas crises ou suas soluções. 


\subsection{Situação Existencial}

A situação existencial como pressuposto filosófico para a abordagem de um modo de ser do homem o modo de ser jurídico permite reconhecer, sem pudores, a importância das condições existenciais de vida as necessidades materiais, o uso e a produção das coisas, o sexo, ou tantas mais que se possam apresentar, e que são reconhecíveis na mundanidade do homem, ou seja, no fato dele existir no mundo e estruturalmente ser-no-mundo-com-outro.

A expressão situação deve aqui ser entendida como conjunto de relações nas quais o ente humano existente se encontra no mundo e com os outros. Este encontrar-se, desde sempre, é o estar em situação. Atende ao que se pode dizer como característica do ser-aí (sempre entendido como ente humano existente) na filosofia da existência: a relação do homem consigo mesmo e com o outro; esta relação exprime-se sempre como possibilidade, sem necessariamente ser garantida, daí as mudanças imprevistas do ser (as "viradas" históricas, por exemplo). Este encontrar-se em situação é sempre um estado de derrelicção, de "lançado ao mundo" abandonado a um determinismo que pode impedir ou-não as ações humanas, já que sempre é possível trabalhar para mudar uma situação.

A filosofia da existência, como preferimos chamar ao modo de pensar que parte da análise da existência (como modo de ser no mundo - numa situação determinada com o outro), vale-se deste instrumental analítico que é comum às diversas correntes existencialistas, mas tem pressupostos e conclusões diferentes das correntes filosóficas do existencialismo em geral. O ente interrogado é o Dasein, em sua estrutura originária e constitutiva (enquanto ser social). A análise existencial é análise das situações mais comuns ou fundamentais em que o homem vem a encontrar-se. E a situação analisada é a de derreliç̧ão econômica. O que chamamos de fenomenologia existencial é o primeiro existencialismo de Heidegger em Ser e tempo e o marxismo humanista com todas as alterações políticas do socialismo real. É a consideração de uma "zona de silêncio" onde não haja a dissolução do ser no valor - é como criar uma zona livre do valor de troca, em que se possa descortinar a possibilidade de uma nova experiência humana experiência de plenitude. Existir significa, então, estar em relação com o mundo, isto é, com as coisas e os outros homens. Neste sentido, existencial é a estrutura originária e constitutiva do ser-aí, que é ser-no-mundo e ser-com-o-outro (ambos são existenciais, como Heidegger 
chama). Assim, situação existencial é o encontrar-se no mundo com o outro, como seres lançados para a morte.

Karl Jaspers vê o homem existente em situação, condicionado por fatos que o impedem de querer e agir de modo diferente daquilo que é (ainda que seja possível a mudança de uma situação pelo trabalho humano). Para ele, há situações-limites "situações que subsistem em sua essência, ainda quando se modifique a sua aparência momentânea e se dissimule sob um véu a sua onipotência: tenho de morrer, de sofrer, tenho de lutar; estou sujeito ao acaso, encontro-me inevitavelmente preso aos laços da culpabilidade"16 - que levam o homem "desde o fundo de si mesmo, a buscar, através do malogro, o caminho do ser" ${ }^{17}$ Neste sentido, existir é sempre existir numa situação determinada; não se pode viver sem luta e sem dor e a todo momento somos levados a decidir em relação à situação que se nos apresenta decidir pelo superficial ou inautêntico, ou pelas determinações profundas da autenticidade.

Aqui se coloca o problema da hermenêutica. Se o ser do ente humano existente é cuidado $^{18}$ nas relações com o mundo e com o outro ele se ocupa e se preocupa para atender ao cuidado de sobreviver e viver, e vencer as situações-limites

o fenômeno jurídico revela-se como modo de ser, estrutura existencial que permite atender ao cuidado. É a compreensão do cuidado que permite desvelar-se o fenômeno jurídico no seu ser - a Justiça.

Em Heidegger a compreensão é sempre prévia - começa com o sentimento de encontrar-se alguém no estado de lançado ao mundo (estado de derrelicção), seguido do sentimento da situação, num mundo de cuidado, ocupação e preocupação. Este situar-se, este encontrar-se é elemento inerente ao ser-aí para the dar seu ser-no-mundo-com-o-outro: a compreensão.

O intérprete, que não é só um observador, mas é ator do drama existencial, tem uma compreensão prévia anterior a toda assimilação de cultura. Essa compreensão é um a priori, antecipa e prefigura toda a nossa experiência - a précompreensão diz respeito à própria natureza do ser-aí (do ente humano existente), é aquela estrutura que o ser existente tem. A analítica do ser-aí chamada também

16. Jaspers, Karl. Introduccion à la philosophie, Paris, Plon, 1950, pp. 19 e ss.

17. Id., p. 22.

18. Heidegger, Martin. El ser y el tiempo, México, Fondo de Cultura Económica, 1951, p. $309:$ "El ser del 'ser-ahí es la cura" 
ontologia fundamental é o exercício do método fenomenológico, a superação da crítica de Kant, que vê o homem só como razão e não como totalidade, onde, além do pensar, há corpo, humor, sentimento; a análise do ser humano em Heidegger é abrangente e esta pré-compreensão é temporal e histórica, portanto não tem a universalidade da razão calculante, dos conceitos do intelecto.

É a partir da analítica do ser-aí que podemos compreender a situação existencial do homem latino-americano e do brasileiro, em particular, num conjunto de relações planetárias onde a "civilização" ocidental está em crise.

A crise do humanismo em Heidegger está ligada à técnica, que na sociedade de organização total, racionalmente dirigida, obscurece a formação do homem como ser cuja cultura terá que compreender o outro, parceiro em um mundo que se revela como inautêntico, já que suas possibilidades de existência não se podem dar. O humanismo em Heidegger não é aquele em que o homem (o próprio, $o$ mesmo) se torna o centro do mundo, mas aquele em que o homem se reapropria do ser-com (modo de ser, num mundo que de outra forma se extinguiria pelo triunfo da civilização técnica). Seu humanismo é uma radical recusa de sentido e valor do niilismo. Há um niilismo reativo esforço para recuperar o ser no mundo do valor da troca, em cuja reapropriação suas possibilidades de existência se dêem como real, naquele ser que assume o ser-para-a-morte a reapropriação é a decisão de assumir a morte e realizar as possibilidades de existência humana.

A resistência à realização do niilismo pathos de autenticidade - é a ordem a qual devem atender não-só os povos latino-americanos, mas também todos os povos do planeta.

É assim que podemos ver o Direito não-somente como criação da sociedade, da cultura. O fundo existencial do Direito tem como traço distintivo a sua identidade universal, de seres-para-a-morte que, derrelictos, procuram em relação sobreviver para viver. A sobrevivência passa pelo econômico, que é um modo de ser, e não um modo de ação do poder. Nisto consiste a universalidade do Direito. No particular, porém, o fato do homem viver numa sociedade e não em outra, viver-emsituação, faz com que o Direito tenha múltiplas manifestações, como produto cultural, diverso e mutável.

São Paulo, janeiro de 1999. 